\title{
Caracterização da Vulnerabilidade Ambiental na Bacia Hidrográfica do Rio Preto, Maranhão - Brasil
}

\author{
Characterization of the Environmental Vulnerability in the Rio Preto River Basin, \\ Maranhão - Brazil
}

\author{
Caracterización de la Vulnerabilidad Ambiental en la Cuenca Hidrográfica de Rio \\ Preto, Maranhão - Brasil
}

\author{
Luiz Carlos Araujo dos Santos ${ }^{1}$ \\ Idevan Gusmão Soares²
}

\begin{abstract}
RESUMO: A vulnerabilidade ambiental é definida como qualquer susceptibilidade do ambiente a um impacto potencial provocado por um uso antrópico. A bacia, localizado na região nordeste do estado do Maranhão, ocupa uma área de 5.235,63 quilômetros quadrados. O desenvolvimento do estudo da vulnerabilidade ambiental desta bacia é importante, pois serve de subsidio ao planejamento ambiental visando a sustentabilidade dos recursos hídricos. O objetivo deste trabalho foi caracterizar a vulnerabilidade ambiental da bacia hidrográfica do Rio Preto, considerando a integração dos solos, a declividade, a estrutura geológica e o uso e cobertura da terra com base na sua estabilidade em relação à morfogênese e à pedogênese almejando contribuir na mitigação de risco da erosão. Para tal, foram utilizadas técnicas de geoprocessamento, que permitiram estabelecer três tipos de unidades ambientais: meios estáveis, onde predomina a pedogênese; meios intergrades, no qual há equilíbrio entre a pedogênese e a morfogênese; e os fortemente instáveis, onde predomina a morfogênese, para assim determinar a intensidade e distribuição da vulnerabilidade na bacia. Verificou-se que $33,59 \%$ da área é vulnerável, $35,61 \%$ é medianamente vulnerável e $30,80 \%$ é representada por áreas estáveis. Identificou-se que o uso da terra para cultivo de soja e eucalipto ao sul da bacia elevou o grau de vulnerabilidade ambiental, pois intensifica a ação erosiva nos solos.
\end{abstract}

PALAVRAS-CHAVE: Vulnerabilidade ambiental. Unidades ambientais. Rio Preto.

ABSTRACT: Environmental vulnerability is defined as any susceptibility of the environment to a potential impact caused by any anthropic use. The basin located in the northeast region of Maranhão state occupies an area of 5,235.63 square kilometers. The study development of the environmental vulnerability of this basin is important because it serves as a subsidy to environmental planning aiming at the sustainability of water resources. The paper objective was to characterize the environmental vulnerability of the Rio Preto basin, considering soil integration, slope, geological structure, and land

\footnotetext{
${ }^{1}$ Dep. História e Geografia e Programa de Pós-Graduação em Geografia - PPGEO da Universidade Estadual do Maranhão - UEMA, Cidade Universitária Paulo VI, Av. Lourenço Vieira da Silva, no 1.000, Jardim São Cristóvão, CEP: 65055-310, São Luís - MA, luizcarlos.cecenuema@gmail.com.

${ }^{2}$ Programa de Pós-Graduação em Geografia - PPGEO pela Universidade Estadual do Maranhão - UEMA, Cidade Universitária Paulo VI, Av. Lourenço Vieira da Silva, nº 1.000, Jardim São Cristóvão, CEP: 65055-310, São Luís - MA, idevanoficial@gmail.com.
} 
use and cover based on its stability in relation to morphogenesis and pedogenesis aiming to contribute to the erosion risk mitigation. For this, geoprocessing techniques were used, which allowed the establishment of three types of environmental units: stable environments, where pedogenesis predominates; intergrades mean, in which there is a balance between pedogenesis and morphogenesis; and the highly unstable, where morphogenesis predominates, to determine the intensity and distribution of vulnerability in the basin. It was found that $33.59 \%$ of the area is vulnerable, $35.61 \%$ are moderately vulnerable and $30.80 \%$ are represented by stable areas. It was found that the use of land for soybean and eucalyptus cultivation in the south of the basin increased the degree of environmental vulnerability, as it intensifies erosive action in soils.

KEYWORDS: Environmental vulnerability. Environmental units. Rio Preto.

RESUMEN: La vulnerabilidad ambiental es definida como cualquier susceptibilidad del ambiente a un impacto potencial provocado por un uso antrópico cualquiera. La cuenca localizada en la región nordeste del estado de Maranhão ocupa un área de 5.235,63 kilómetros cuadrados. El desenvolvimiento del estudio de la vulnerabilidad ambiental de esta cuenca es importante, pues sirve de subsidio a la planificación ambiental visando la sostenibilidad de los recursos hídricos. El objetivo de este trabajo fue caracterizar la vulnerabilidad ambiental de la cuenta hidrográfica de Rio Preto, considerando la integración de los suelos, declividad, estructura geológica y uso de cobertura de la tierra teniendo como base su estabilidad en relación a la morfogénesis y la pedogénesis, deseando contribuir en la mitigación del riesgo a la erosión. Para tal, se utilizaron técnicas de geoprocesamiento, que permitieron establecer tres tipos de unidades ambientales: medios estables, donde predomina la pedogénesis; medios intergrades, en el cual hay equilibrio entre pedogénesis y morfogénesis; $y$ los fuertemente estables, donde predomina la morfogénesis, para así determinar la intensidad y la distribución de la vulnerabilidad en la cuenca. Se verificó que 33,59\% del área son vulnerables, 35,61\% son medianamente vulnerables y 30,80\% son representadas por áreas estables. Se identificó que el uso de la tierra para cultivo de soja y eucalipto al sur de la cuenca elevó el grado de vulnerabilidad ambiental, pues intensifica la acción erosiva en los suelos.

PALABRAS-CLAVE: Vulnerabilidad ambiental. Unidades ambientales. Rio Preto.

\section{INTRODUÇÃO}

Inicialmente, o conceito de vulnerabilidade foi proposto por Le Grand (1964), nos Estados Unidos e, posteriormente, em 1970, na França por Albinet e Margat (1970). Durante as décadas de 1980 e 1990 este conceito foi difundido mais amplamente com a publicação de outros trabalhos, tais como: Drastic (ALLER et al., 1987); God (FOSTER; HIRATA, 1988); Avi (VAN STEMPVOORT; EWERT; WASSENAAR, 1992); Sintacs (CIVITA; DE MAIO, 1997); e Epik (DOERFLIGER; ZWAHLEN, 1997). A partir destas publicações, o conceito se consolidou, resultando em muitas interpretações para seu significado (FRANCISCO, 2018).

Neste percurso histórico de construção teórico-conceitual, diversas dimensões e termos foram associados à vulnerabilidade para defini-la, dentre elas: fragilidade, risco, susceptibilidade, perigo, exposição, sensibilidade, e capacidade adaptativa ou de resposta. Além da introdução destes termos, há uma diversidade de enfoques de estudo, dentre os 
quais: vulnerabilidade ambiental, natural, social e socioambiental, assim como métodos e índices para mesurar e representar cartograficamente o grau de vulnerabilidade.

Nesse contexto, entende-se que a vulnerabilidade natural mostra a pré-disposição do ambiente frente a fatores naturais como: geomorfologia, estrutura geológica, solos e a sua estabilidade em relação à morfogênese e à pedogênese, enquanto que a vulnerabilidade ambiental é intensificada pela pressão antrópica (GRIGIO, 2003; KLAIS et al., 2012).

Conforme Grigio (2003), a vulnerabilidade natural abrange os aspectos naturais da paisagem (solos, geomorfologia, geologia e vegetação). Já a vulnerabilidade ambiental aborda essas variáveis e inclui a ação da sociedade (uso e ocupação do solo), elemento considerado pelo autor como de grande importância em qualquer tipo de análise ambiental.

Nos estudos relacionados à vulnerabilidade natural é comum associá-la a processos erosivos. Com efeito, a erosão é um processo natural de degradação, decomposição, transporte e deposição de materiais de rochas e solos e é a principal forma de degradação dos solos (WINCANDER; MONROE, 2009). Desta forma, independentemente da atuação antrópica os processos erosivos irão ocorrer e imanente a eles o intemperismo físicoquímico.

Entende-se que na natureza ocorre uma predisposição para a degradação dos solos decorrente da atuação erosiva (eólica e pluvial), assim como movimentos de massa e assoreamento de rios, ou seja, processos naturais que o ser humano não determina, porém a atuação antrópica sem o devido planejamento pode intensificar esses fenômenos, por exemplo, o desmatamento de extensas áreas para atividade agrícola, deixando o solo exposto e suscetível à atuação mais intensa dos agentes erosivos ou ainda a remoção da mata ciliar das margens dos rios intensificando o assoreamento. Neste viés, surge a vulnerabilidade ambiental decorrente da intensificação advinda da pressão antrópica.

Conforme Spörl (2007), os estudos relacionados à vulnerabilidade dos ambientes são importantes para o planejamento ambiental, pois se trata de um instrumento cuja finalidade é identificar e analisar os ambientes em função de seus diferentes níveis de susceptibilidade, proporcionando, assim, uma melhor definição das diretrizes e ações a serem implementadas no espaço físico-territorial.

Devido à complexidade em relação ao meio ambiente é necessária uma abordagem integrada para seu entendimento visando a conservação. O planejamento ambiental, dentro dessa ótica, é um excelente instrumento de gestão, pois estabelece diretrizes e metas a serem alcançadas dentro de um cenário temporal (FERREIRA, 2016). Neste contexto, os Sistemas de Informação Geográfica (SIGs) são úteis e eficazes na avaliação da vulnerabilidade ambiental, pois diversas camadas de informações, por exemplo, solos, vegetação, relevo, uso e ocupação etc., podem ser integrados e processados. 
Em face ao exposto, o trabalho tem como objeto de estudo a bacia hidrográfica do Rio Preto, sendo esta, uma sub-bacia da bacia hidrográfica do Rio Munim. A bacia está situada entre as coordenadas geográficas: $3^{\circ} 40^{\prime}-4^{\circ} 00^{\prime} \mathrm{S}$ e $42^{\circ} 56^{\prime}-43^{\circ} 52^{\prime} \mathrm{O}$. Após percorrer cerca de 270 quilômetros, deságua no Rio Munim, na localidade de Nina Rodrigues (Figura 1).

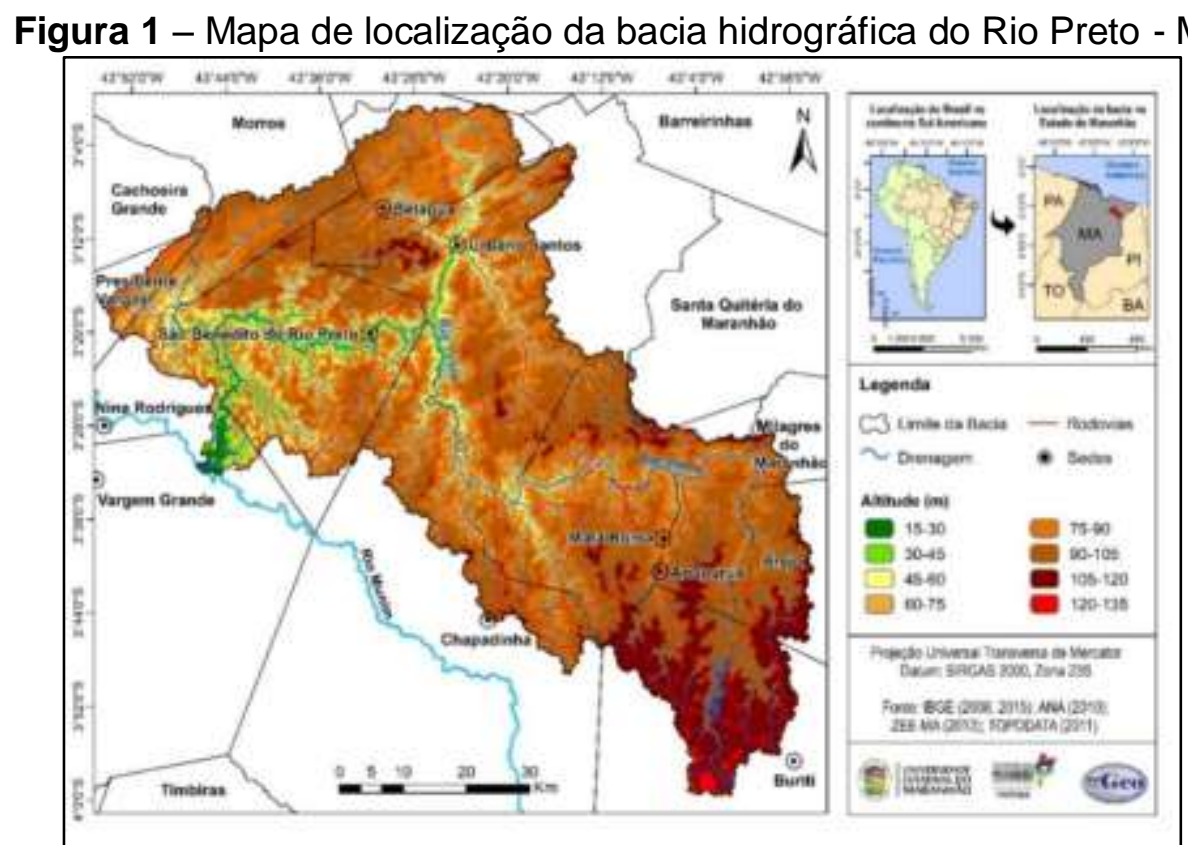

Organização: autores.

A gestão ambiental da bacia em questão está sobre a responsabilidade do Comitê de Bacia Hidrográfica do Rio Munim (MARANHÃO, 2013). Este órgão tem como missão promover a gestão integrada dos recursos hídricos da Bacia Hidrográfica do Rio Munim, articulando as políticas públicas e setoriais correlatas e integrando o planejamento e as ações das instâncias do Sistema Estadual de Gerenciamento da Bacia. Embora tenha essa missão, o Comitê de Bacia Hidrográfica do Rio Munim não é atuante.

Desde a década de 1980 a área da bacia tornou-se uma fronteira agrícola para onde se direcionaram projetos de expansão do agronegócio. As transformações e mudanças na dinâmica da bacia hidrográfica são observadas atualmente, devido a processos decorrentes dos usos e da ocupação da terra, ensejados pelas culturas agrícolas, com destaque para os cultivos de soja e eucalipto. As empresas relacionadas ao agronegócio têm cultivado extensas áreas com esses monocultivos, deixando expressivas áreas suscetíveis à aceleração de processos erosivos, possibilitando o assoreamento do leito do Rio Preto.

As queimadas para limpeza das áreas agrícolas e áreas de pastagem são outras atividades que também favorecem o nível de degradação da bacia. Neste sentido, ressaltase que a vulnerabilidade ambiental da área de pesquisa está relacionada à intensificação 
dos processos erosivos, principalmente decorrente das atividades agrícolas sem o devido planejamento ambiental. Os camponeses que vivem nos municípios banhados pela bacia, por sua vez, fazem o uso da terra para cultivos agrícolas, com destaque para as culturas temporárias e criação extensiva de animais.

Diante do exposto, o objetivo deste trabalho foi caracterizar a vulnerabilidade ambiental da bacia hidrográfica do Rio Preto, considerando a integração dos solos, declividade, estrutura geológica e uso e cobertura da terra com base na sua estabilidade em relação à morfogênese e à pedogênese, almejando contribuir na mitigação de risco à erosão.

\section{PROCEDIMENTOS METODOLÓGICOS}

\section{Mapeamento dos Aspectos Geoambientais}

Para alcançar o objetivo do trabalho realizou-se, primeiramente, a etapa de extração da rede de drenagem e delimitação da bacia. Para esse fim, utilizou-se o Quantum GIS (QGIS) 2.18.16 e os dados de altimetria do Shuttle Radar Topography Mission (SRTM) reamostrados para 30 metros de resolução espacial. Esses dados são do tipo Modelo Digital de Elevação (MDE) e estão disponíveis para download no site do (INP) Instituto Nacional de Pesquisas Espaciais (2011), TOPODATA - Banco de Dados Geomorfométricos do Brasil. Para o trabalho, foram utilizados os dados SRTM das folhas n'03S45_ZN e 03S435_ZN e as ferramentas do provedor Terrain Analysis Using Digital Elevation Models (TauDEM).

Para a produção do mapa de unidades geológicas, recorreu-se à base de dados vetoriais da (CPRM) Companhia de Pesquisa de Recursos Minerais (2012). Já para o mapeamento dos tipos de solos, utilizou-se a base de dados do Zoneamento Ecológico Econômico do Estado do Maranhão. Ambos os dados shapefiles utilizados foram disponibilizados numa escala de 1:750.000 e 1:1000.000, respectivamente. (INSTITUTO MARANHENSE DE ESTUDOS SOCIOECONÔMICOS E CARTOGRÁFICOS, 2019).

Após a obtenção dos vetores de unidades geológicas, possuindo o sistema geodésico SIRGAS 2000, sob o código European Petroleum Survey Group (EPSG) 4674 e os dados de solos (EPSG: 4326, WGS 84) por meio de download nos sites mencionados, os mesmos foram importados para o ArcGIS 10.2.2 (licença EFL999703439) para efetuar os procedimentos de reprojeção para o sistema geodésico SIRGAS 2000 zona 23S, projeção Universal Transversa de Mercator e recorte dos planos de informação para o limite da bacia.

Para o mapeamento do gradiente de declividade utilizaram-se os dados de altimetria que foram empregados na etapa de extração e delimitação da bacia. Estes dados foram importados no ArcGIS e, a seguir, visando obter a declividade, utilizou-se a ferramenta 
Slope (Declive), que pertence ao conjunto de ferramentas Raster Surface (Superfície Raster). A declividade obtida pela ferramenta Slop foi processada para ser dada em termos percentuais.

Já tratando da definição das classes de declividade, adotou-se a classificação proposta por Lepsch (1991). Em conformidade com a metodologia utilizada, a declividade foi dividida em sete classes, que possuem entre si distintos intervalos. De acordo com os autores, as classes de relevo são divididas em: Plano (0-2\%), Suave Ondulado (2-5\%), Moderadamente Ondulado (5-10\%), Ondulado (10-15\%), Forte Ondulado (15-45\%), Montanhoso (45-70\%), Escarpado (>70\%).

Quanto ao mapeamento do uso e cobertura da terra, realizou-se, primeiramente, a aquisição de imagens orbitais (EPSG: 32723, WGS 84 / UTM zona 23S) do satélite Landsat8, sensor Operational Land Imager (OLI) de órbitas/ponto 220/62 e 220/63 datadas de 17/07/2017. Essas imagens foram adquiridas junto ao Serviço de Levantamento Geológico Americano (UNITED STATES, 2017).

Com a aquisição das imagens, efetuou-se, no QGIS, a reprojeção para SIRGAS 2000 / UTM zona $23 S$ e recorte dos dados para o limite da bacia. No SIG, as imagens passaram pelo processo de empilhamento das bandas $6(R), 5(G)$ e 4(B). Por conseguinte, recorreu-se ao método de classificação supervisionada por regiões homogêneas para o mapeamento do uso e cobertura da terra. Para esse processamento as imagens foram importadas para 0 SIG SPRING 5.5.2.

No SIG, efetuaram-se aplicações de contrastes lineares nas imagens e procedeu-se à etapa de segmentação da imagem por crescimento de região. Para esse processo foi estabelecido como parâmetros de similaridade 10 e área mínima 30.

Após a realização da segmentação, procedeu-se à etapa de classificação supervisionada baseada nas regiões obtidas no processo de segmentação anterior. Para tal, foram definidas as classes de uso e cobertura da terra a serem identificadas, sendo que, para este trabalho, estipularam-se oito classes, a saber: corpo d'água, área urbana, área de eucalipto, área de soja, cobertura vegetal, solo exposto, não observado (áreas com presença de nuvens e queimadas) e paleodunas.

Para as classes identificadas foi adquirido um quantitativo de amostras de treinamento que subsidiaram a execução do algoritmo de classificação supervisionada por regiões homogêneas. Dessa forma, efetuou-se o reconhecimento automático das classes de uso e cobertura da terra.

O algoritmo utilizado foi o Battacharya, uma vez que permite a supervisão e controle do usuário, através do treinamento. "A principal característica deste algoritmo consiste em medir a separabilidade estatística entre um par de classes espectrais através da distância 
média entre as suas distribuições de probabilidades" (BARROS; STRAUCH, 2016, p. 15). O limiar de aceitação utilizado neste algoritmo foi de 99,9\%.

Para validar o mapeamento realizou-se trabalho de campo que constituiu no emprego de técnicas que permitiram checar, observar e avaliar as classes mapeadas. Dessa maneira, priorizou-se a observação dos componentes ambientais (solos, vegetação, relevo etc.) in loco, seguida de registros fotográficos e da coleta de pontos por meio de sistema de navegação por satélite obtida por GPSMAP Garmin 64, em locais pré-determinados no QGIS.

Salienta-se que a escala adotada para o mapeamento do uso e cobertura da terra e declividade foi de 1:250.000, a exceção foram os mapas de unidades geológicas e solos possuindo escala de 1:750.000 e 1:1000.000 que foram apenas recortados para o limite da bacia. Portanto, foram os dados possíveis identificados para o estado do Maranhão.

\section{Mapeamento da Vulnerabilidade Ambiental}

Para identificar as áreas de vulnerabilidade na bacia do Rio Preto, produziu-se o mapa de vulnerabilidade ambiental utilizando o ArcGIS. Para esse fim, recorreu-se à metodologia proposta por Crepani et al. (2001), desenvolvida a partir dos princípios da Ecodinâmica de Tricart (1977) e estabeleceu três tipos de unidades ambientais, sendo eles: meios estáveis, predomina a pedogênese; meios intergrades, no qual há equilíbrio entre pedogênese e morfogênese; e os fortemente instáveis, em que predomina a morfogênese. Assim, determinou-se a intensidade e distribuição da vulnerabilidade ambiental na área-objeto.

Considerando os processos morfodinâmicos, foram atribuídos valores que variaram de 1,0 a 3,0 (no total, as áreas podem ser enquadradas em 21 valores de vulnerabilidade). Nas situações onde há o predomínio dos processos de pedogênese se atribuem valores próximos de 1,0; nas situações intermediárias se atribuem valores ao redor de 2,0 e em situações de predomínio dos processos de morfogênese se atribuem valores próximos de 3,0 .

Para atribuir valor de vulnerabilidade a cada unidade territorial básica foi adotada uma equação (1) empírica proposta por Crepani et al. (2001). Equação (1): $V=(G+P+D+U c t) / 4$. Onde: V: vulnerabilidade; G: vulnerabilidade para o tema geologia; P: vulnerabilidade para o tema pedologia; D: vulnerabilidade para o tema declividade; Uct: vulnerabilidade para o tema uso e cobertura da terra.

Quanto à execução do mapeamento da vulnerabilidade ambiental da bacia, algumas etapas fundamentais foram realizadas tendo como referência a metodologia proposta por Crepani et al. (2001). Na sequência, serão descritas as etapas que foram necessárias para produção do mapa de vulnerabilidade ambiental da bacia hidrográfica do Rio Preto. 
De antemão, realizou-se uma revisão bibliográfica sobre a temática da vulnerabilidade ambiental e, logo após a produção dos mapas geoambientais, procedeu-se a análise individual de cada uma das informações contidas neles no que tange aos elementos físicos da paisagem para avaliação da estabilidade ou vulnerabilidade das unidades de paisagens. Considerou-se a relação entre os processos de morfogênese e pedogênese por meio da análise integrada dos litotipos, dos solos, da declividade e do uso e cobertura da terra.

Em relação às temáticas mencionadas, o Quadro 1 apresenta os critérios dos planos de informação que foram levados em consideração para a análise e definição da categoria morfodinâmica da unidade de paisagem, em outras palavras, os critérios que foram considerados para definir a vulnerabilidade do solo a processos erosivos.

Quadro 1 - Planos de informação - variáveis e critérios

Geologia
Levou-se em consideração o grau de coesão das rochas.
Em rochas pouco coesas podem prevalecer os processos
erosivos, modificadores das formas de relevo
(morfogênese), enquanto nas rochas bastante coesas
devem prevalecer os processos de intemperismo e
formação de solos (pedogênese).
Cobertura Vegetal/Uso da Terra
A densidade de cobertura vegetal é um fator de proteção
da unidade contra os processos morfogenéticos, que se
traduzem na forma de erosão. Por isso, quanto mais
intensa a cobertura vegetal, maior a estabilidade
encontrada na unidade de paisagem. Já as áreas de soja,
eucalipto, urbanas e solo exposto compõem as classes
que são qualificadas como de alta vulnerabilidade devido
à retirada da cobertura vegetal e modificação da
paisagem natural, permitindo que o solo fique exposto às
intempéries e prejuízos provocados por tais usos da terra.

\section{Declividade}

Desta variável considera-se a inclinação das vertentes e a dinâmica do escoamento. Quanto maior a inclinação das vertentes, mais expressiva é a ação dos agentes erosionais; logo, mais intensa é a dinâmica do escoamento da água.

\section{Pedologia}

Considera-se a maturidade dos solos. A maturidade indica claramente se prevalecem os processos erosivos da morfogênese que geram solos jovens, pouco desenvolvidos, ou se as condições de estabilidade permitem o predomínio dos processos de pedogênese, gerando solos maduros, lixiviados e bem desenvolvidos.

Fonte: Crepani et al. (2001), Tagliani (2003) e Dias (2012).

A partir da determinação dos critérios para a definição da estabilidade, equilíbrio ou vulnerabilidade das unidades de paisagens, procedeu-se à etapa de atribuição dos pesos, levando-se em consideração os critérios apresentados no Quadro 1. Nesse sentido, as informações contidas em cada tema receberam uma nota conforme a vulnerabilidade de cada elemento presente na área-objeto a processos de perda de solos ou atuação antrópica que favorecem a ocorrência de deslizamentos, desmoronamentos, erosões laminares e alagamentos, dentre outros.

Diante do exposto, a Tabela 1 apresenta os valores utilizados para estabelecer a vulnerabilidade, bem como os critérios estabelecidos no Quadro 1, com ressalva para algumas adaptações necessárias para a bacia, no que diz respeito à metodologia utilizada. 
Tabela 1 - Pesos de vulnerabilidade para as informações dos temas de geologia, solos, declividade e uso e cobertura da terra

\begin{tabular}{llllllll}
\hline Uso e cobertura & Vuln. & Solos & Vuln. & Geologia & Vuln. & Decliv. & Vuln. \\
\hline Área urbana & 3,0 & $\begin{array}{l}\text { Neossolos } \\
\text { Quartzarênicos }\end{array}$ & 3,0 & $\begin{array}{l}\text { Depósitos } \\
\text { Eólicos } \\
\text { Continentais } \\
\text { Antigos }\end{array}$ & 2,0 & $<2 \%$ & 1,0 \\
\hline Área de soja & 3,0 & $\begin{array}{l}\text { Plintossolos } \\
\text { Pétricos }\end{array}$ & 3,0 & $\begin{array}{l}\text { Formação } \\
\text { Codó }\end{array}$ & 3,0 & $2-5 \%$ & 1,0 \\
\hline Solo exposto & 3,0 & $\begin{array}{l}\text { Plintossolos } \\
\text { Argilúvicos }\end{array}$ & 3,0 & $\begin{array}{l}\text { Grupo } \\
\text { Itapecuru }\end{array}$ & 3,0 & $5-10 \%$ & 2,0 \\
\hline Área de eucalipto & 3,0 & $\begin{array}{l}\text { Argissolos } \\
\text { Vermelho- } \\
\text { concrecionários }\end{array}$ & 2,0 & $\begin{array}{l}\text { Depósitos } \\
\text { Aluvionares }\end{array}$ & 2,0 & $10-15 \%$ & 2,0 \\
\hline Corpo de água & 1,0 & $\begin{array}{l}\text { Latossolos } \\
\text { Amarelos }\end{array}$ & 1,0 & $\begin{array}{l}\text { Grupo } \\
\text { Barreiras }\end{array}$ & 3,0 & $>35 \%$ & 3,0 \\
\hline Não observado & 2,0 & - & - & - & - & - & - \\
\hline Paleodunas & 1,0 & - & - & & - & - & - \\
\hline Cobertura vegetal & 1,0 & - & - & - & - & - \\
\hline
\end{tabular}

Fonte: Crepani et al. (2001).

Porém, para atribuir os pesos estipuladas para as classes das temáticas foi necessário a realização de duas etapas no ArcGIS: a primeira consistiu em converter todos os shapefiles em arquivo raster; após essa conversão, procedeu-se à última etapa, que teve por objetivo reclassificar os valores/informações para a inserção das notas. Utilizou-se, para esse fim, a ferramenta de reclassificação (Reclassify) do SIG.

Após a atribuição das notas, para os valores/informações dos temas, realizada na etapa anterior, apresentaram-se como resultado mapas de vulnerabilidade para os temas: geologia, solos, declividade e uso e cobertura da terra. Procedeu-se, então à etapa de atribuição dos pesos dos temas, de modo a diferenciar o grau de importância e correlação com o fenômeno em questão (susceptibilidade erosiva). Para o tema declividade, foi estabelecido o peso 0,30 , para geologia 0,15 e para solos e uso e cobertura da terra 0,25 e 0,30 , respectivamente.

Depois da organização de todos os mapas de vulnerabilidade separadamente, foi feita a integração dos mesmos através da operação de álgebra de mapas. Nessa etapa, utilizouse a calculadora raster para inserir a equação (1) de soma, que relaciona os mapas de vulnerabilidade e os pesos dos temas estabelecidos anteriormente. Esse procedimento permitiu a integração dos dados que foram obtidos em cada mapa de vulnerabilidade separadamente, resultando, finalmente, no mapa síntese de vulnerabilidade ambiental.

$\mathrm{Na}$ legenda do mapa síntese de vulnerabilidade ambiental utilizou-se a seguinte nomenclatura: estável (nota 1,15 - 1,40), medianamente vulnerável (nota 1,40 - 1,75) e vulnerável (nota 1,75 - 3). Utilizou-se a apresentação das informações no intervalo de 3 classes e o método de classificação de dados foi do tipo Quebras Naturais (jenks). 


\section{RESULTADOS E DISCUSSÃO}

\section{Caracterização da Área de Estudo}

O clima da região, de acordo com a classificação feita pelo laboratório de meteorologia da Universidade Estadual do Maranhão, caracteriza-se como subúmido, com totais pluviométricos anuais que variam de 1.600 a 2.000 milímetros (PRESOTI, 2008). A distribuição das chuvas não é homogênea ao longo de sua extensão, observando-se duas estações bem distintas: uma chuvosa, no primeiro semestre, e outra seca, no segundo semestre do ano. Considerando-se os dados do (INMET) Instituto Nacional de Meteorologia (2019), da estação automática de Chapadinha (82382), a temperatura ambiente da áreaobjeto apresenta uma média máxima anual de $33^{\circ} \mathrm{C}$ e temperatura mínima média anual de $22,70^{\circ} \mathrm{C}$.

A bacia tem um perímetro de 785.97 quilômetros e apresenta a disposição da sua rede de drenagem na forma dendrítica, com ramificações irregulares de cursos de água em todas as direções. Os ângulos de inserção entre os canais de drenagem secundários e os principais são os mais variados. Esse modelo expressa uma característica básica das bacias sedimentares, denotando a presença de rochas sedimentares com pouca resistência à erosão (MARANHÃO, 2006).

A bacia do Rio Preto apresenta as unidades geológicas: Formação Codó (12,04 quilômetros quadrados), Grupo Itapecuru (1.644,51 quilômetros quadrados), Grupo Barreiras (1.381,68 quilômetros quadrados), Depósitos Eólicos Continentais Antigos (1.945,04 quilômetros quadrados), e Depósitos Aluvionares (252,36 quilômetros quadrados), em conformidade com a Figura 2.

A Formação Codó é constituída, dominantemente, por folhelhos negros, argilitos calcíferos, pelitos, calcário e arenito com gipso de ambiente lagunar. Já o Grupo Itapecuru é um conjunto de formações composto por variados tipos de rochas, como arenitos argilitos, siltitos, folhelhos intercalados com arenitos depositados em vários ambientes (fluvial, deltaico e lagunar). O Grupo Barreiras é constituído por arenitos com inúmeras intercalações de folhelhos de origem fluvial, estuarina e marinha. Já os Depósitos Eólicos Continentais Antigos são caracterizados por campos de dunas fixas, constituídas por areias esbranquiçadas, de granulometria fina a média, bem selecionadas e maturas (LOPES; TEIXEIRA, 2013). Os autores expõem ainda os Depósitos Aluvionares, que são constituídos por areias e argilas que estão sendo transportadas e depositadas pelos rios e igarapés desde os últimos 10 mil anos. 
Figura 2 - Mapa de geologia da bacia hidrográfica do Rio Preto - MA

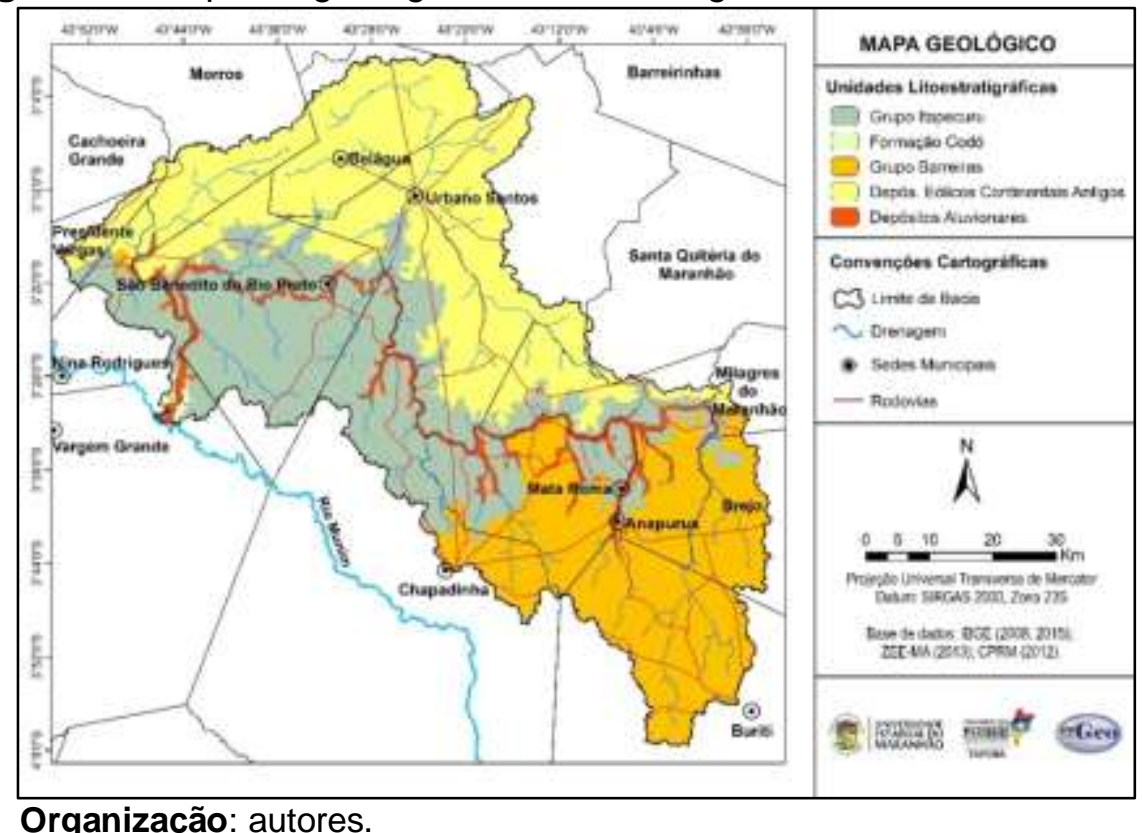

A declividade da bacia caracteriza-se por formas de relevo situadas entre Plano a Forte Ondulado. As maiores declividades estão situadas às margens dos canais de drenagens da bacia, principalmente nos canais de $4^{\mathrm{a}}$ a $8^{\mathrm{a}}$ ordem. Essas altas declividades são bastante expressivas na região da bacia que compreende o município de São Benedito do Rio Preto e Nina Rodrigues (Figura 3).

Figura 3 - Mapa de declividade da bacia hidrográfica do Rio Preto - MA

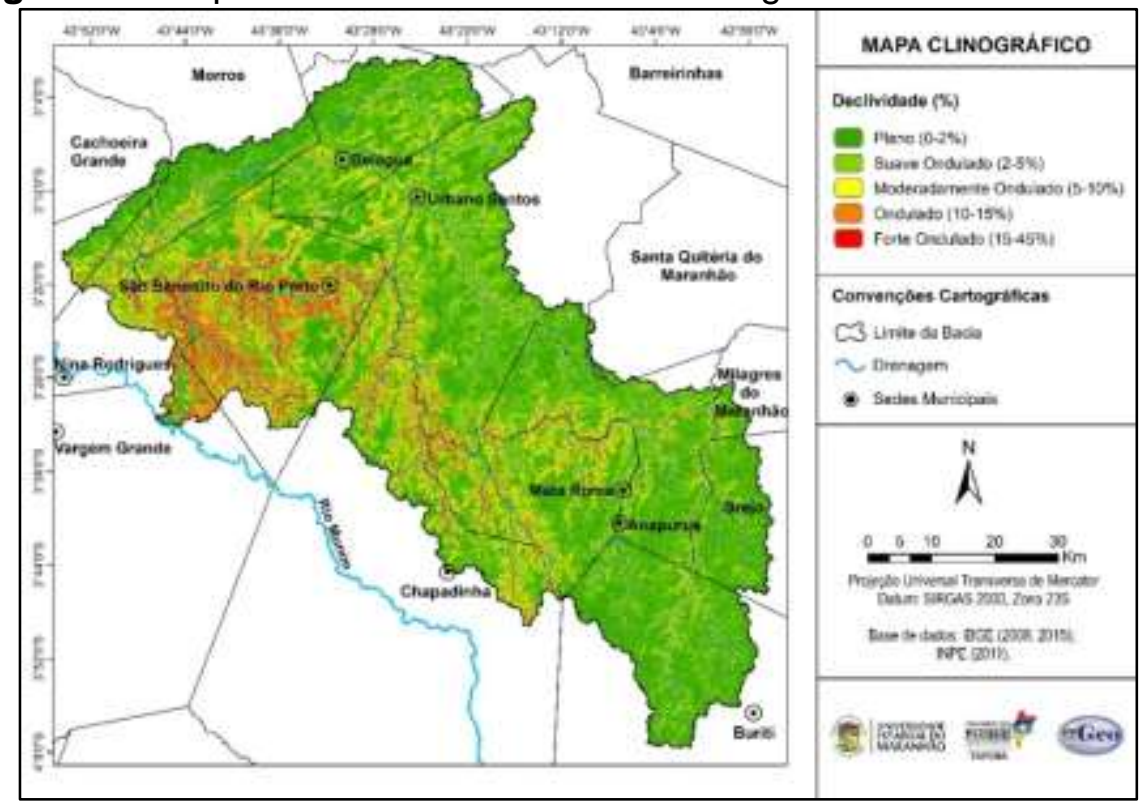

Organização: autores.

As áreas planas correspondem a $0-2 \%$ e suave ondulada $2-5 \%$. São as regiões onde se encontram as atividades agrícolas, assim como o cultivo de eucalipto e ao Norte da bacia 
encontram-se as paleodunas. Já as áreas mais declivosas, ondulado $10-15 \%$ e forte ondulado $>15 \%$, estão em áreas marginais ao Rio Preto e seus afluentes, onde se encontra uma vegetação nativa mais conservada, principalmente, a oeste da bacia. Já no exutório da bacia encontra-se um relevo perpassando de plano a moderadamente ondulado, onde se observa a presença da savana arborizada.

Os solos na bacia estão representados pelas seguintes classes: Argissolos Vermelhoconcrecionários (1.672,05 quilômetros quadrados), Latossolos Amarelos (2.755,69 quilômetros quadrados), Neossolos Quartzarênicos (364,02 quilômetros quadrados), Plintossolos Pétricos (3,38 quilômetros quadrados), e Argilúvicos (440,49 quilômetros quadrados), cuja classificação encontra-se em conformidade com a (Embrapa) Empresa Brasileira de Pesquisa Agropecuária (BATISTELLA et al., 2013).

Os Argissolos Vermelho-concrecionários estão presentes na região da bacia, correspondendo a 31,94\%, envolvendo áreas dos municípios de Anapurus, Chapadinha, Mata Roma, Urbano Santos, Belágua, São Benedito do Rio Preto, Milagres do Maranhão, Morros, Buriti, Brejo, Presidente Vargas e Nina Rodrigues.

A Embrapa expõe que esses solos apresentam limitações ao manejo e à mecanização, decorrentes da grande quantidade de calhaus e cascalhos na superfície e dentro dos perfis. Por outro lado, são relativamente bem drenados, retêm umidade e matéria orgânica de maneira razoável e são bem resistentes à erosão. (BATISTELLA et al., 2013).

Os Latossolos Amarelos, de acordo com Batistella et al. (2013), são solos profundos, bem a acentuadamente drenados, com horizontes de coloração amarelada, de textura média e argilosa, sendo predominantemente distróficos, ocorrendo também álicos, com elevada saturação de alumínio e teores de nutrientes muito baixos. São encontradas em áreas de topos de chapadas, ora baixas e dissecadas, ora altas e com extensões consideráveis, apresentando relevo plano com pequenas e suaves ondulações, tendo como material de origem mais comum as coberturas areno-argilosas e argilosas, derivadas ou sobrepostas às formações sedimentares. Na área de pesquisa, esses solos encontram-se nos municípios de Anapurus, Chapadinha, Mata Roma, Urbano Santos, Belágua, São Benedito do Rio Preto, Milagres do Maranhão, Morros, Buriti, Brejo, Santa Quitéria do Maranhão, Cachoeira Grande, Presidente Vargas e Nina Rodrigues, o que envolve 52,63\% da área da bacia (Figura 4).

Quanto aos Neossolos Quartzarênicos, Batistella et al. (2013) explica que são solos minerais, derivados de sedimentos arenoquartzosos do Grupo Barreiras do período do Terciário e sedimentos marinhos do período do Holoceno. Nos municípios banhados pela bacia, geralmente, são profundos a muito profundos, com textura areia ou areia franca, são excessivamente drenados e pouco desenvolvidos, devido à baixa atuação dos processos 
pedogenéticos e pela resistência do material de origem ao intemperismo. Na bacia, encontram-se nos municípios de Morros e Belágua com uma cobertura de 6,95\% da bacia.

Figura 4 - Mapa de solos da bacia hidrográfica do Rio Preto - MA

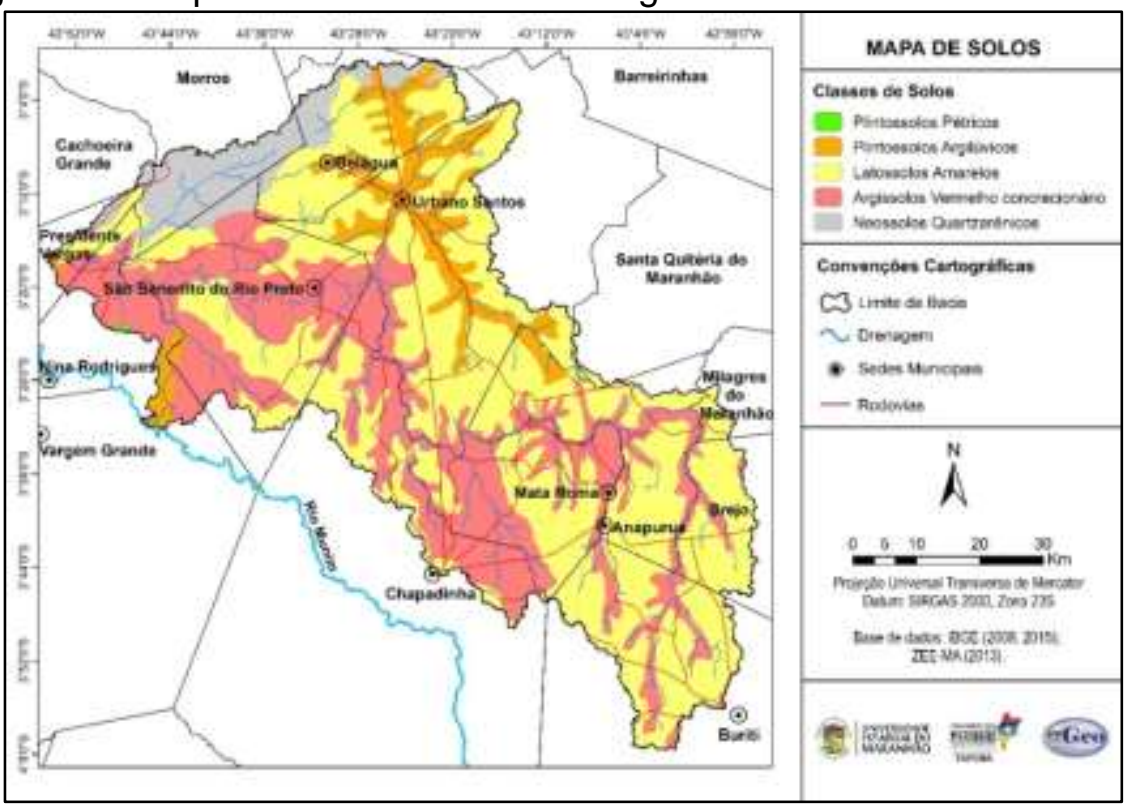

Organização: autores.

Quanto aos Plintossolos, Batistella et al. (2013) afirma que são solos de textura média e argilosa, que têm restrição à percolação d'água, sujeitos ao efeito temporário do excesso de umidade e se caracterizam por apresentar horizonte plíntico, podendo ser álicos, distróficos e eutróficos. Na bacia, ocupam áreas de relevo predominantemente plano ou suavemente ondulado e se originam a partir das formações sedimentares, e ocorrem principalmente em Nina Rodrigues, tanto o Plintossolos Pétricos (0,06\%) como o Argilúvicos $(8,41 \%)$.

$\mathrm{Na}$ área de pesquisa, existem diversos tipos de uso e cobertura da terra, dentre eles, áreas de soja (335,75 quilômetros quadrados), sendo essa a cultura mais expressiva, alocando extensas áreas para cultivo na região sul e leste da bacia. Além da soja, também há áreas de solo exposto, que são terrenos onde ocorreu a supressão da cobertura vegetal, correspondendo a uma área de 596,43 quilômetros quadrados. Os corpos d'água presentes na pesquisa (34,17 quilômetros quadrados), por sua vez, dizem respeito a lagoas, lagos, riachos, açudes e o próprio Rio Preto (Figura 5).

As áreas urbanas (41,22 quilômetros quadrados) correspondem aos espaços identificados com residências padronizadas, oriundas de financiamentos, ou áreas residenciais consolidadas, bem como prédios e outras instalações, onde normalmente se destacam atividades terciárias. Compreendem também áreas onde se encontram as sedes municipais, vilas e/ou povoados. Já a classe denominada Não-observado (33,88 quilômetros 
quadrados) abrange as áreas que não foram observadas devido à presença de nuvens e sua respectiva sombra e áreas queimadas.

Figura 5 - Mapa de uso e cobertura da terra da bacia hidrográfica do Rio Preto - MA

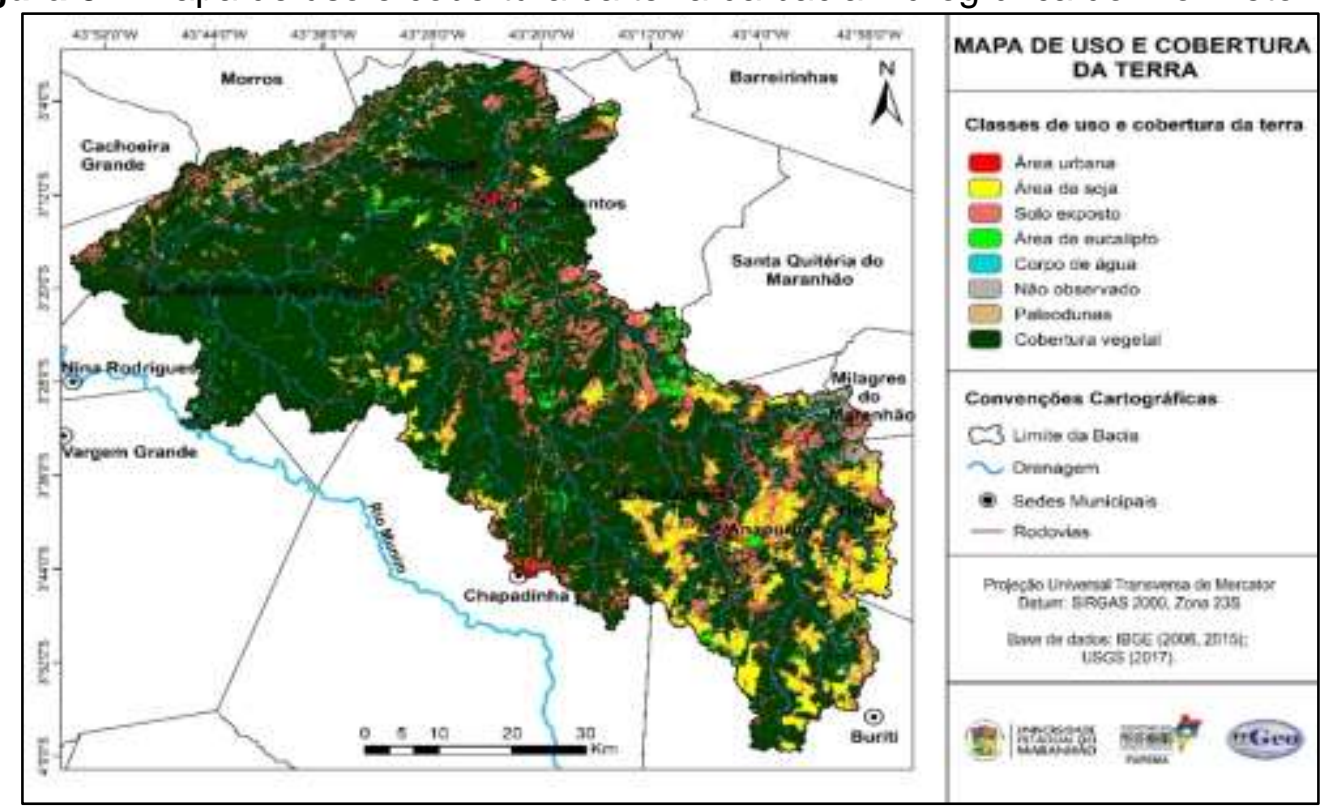

Organização: autores.

O cultivo de eucalipto na área de pesquisa ocupa uma área de 107 quilômetros quadrados e serve como matéria prima para a produção do carvão vegetal e para produção de celulose, matéria prima usada na fabricação de guardanapos, papel higiênico e papéis para imprimir e escrever, entre outros itens. Já a cobertura vegetal da bacia diz respeito a áreas com padrão de cobertura da terra compatíveis com as diferentes fisionomias que compõem o Bioma Cerrado, ainda que apresentem algum nível de alteração em relação à paisagem original, em função da presença de atividades produtivas pouco intensivas ou de subsistência, como as pastagens naturais.

Na bacia do Rio Preto a vegetação é representada pelo Cerradão, Cerrado sensu stricto, Campo Limpo, Campo Cerrado, e ocupa uma área de 3992,08 quilômetros quadrados, sendo a classe mais abrangente na bacia. Já as paleodunas (95,09 quilômetros quadrados), situam-se ao norte da bacia. São tidas como cobertura da terra, pois não foi evidenciado nenhum tipo de uso da terra nessa região. (BATISTELLA et al., 2013).

\section{Caracterização das Áreas de Vulnerabilidade Ambiental}

Com a integração das temáticas decorrentes da utilização do método de Crepani et al. (2001), identificou-se a variação da vulnerabilidade ambiental da bacia. Os procedimentos permitiram verificar que $1.758,46$ quilômetros quadrados da área total da bacia pode ser 
classificada como vulnerável. A área é ocupada predominantemente pela classe medianamente vulnerável, o que representa 1.864,55 quilômetros quadrados de sua extensão total, ao passo que 1.612,62 quilômetros quadrados são representados por áreas estáveis, onde predomina o processo morfodinâmico mais lento (Tabela 2).

Tabela 2 - Classes de vulnerabilidade da bacia e suas respectivas concentrações

\begin{tabular}{lll}
\hline Classes de vulnerabilidade & Áreas $\left.\mathbf{( k m}^{2}\right)$ & Áreas $(\%)$ \\
\hline Estável & $1.612,62$ & 30,80 \\
Medianamente vulnerável & $1.864,55$ & 35,61 \\
Vulnerável & $1.758,46$ & 33,59 \\
Total & $\mathbf{5 . 2 3 5 , 6 3}$ & $\mathbf{1 0 0 , 0 0}$ \\
\hline
\end{tabular}

Organização: autores.

As áreas estáveis constituem as unidades representadas por maior estabilidade ambiental, e estão associadas à presença de cobertura vegetal, relevo plano a suave ondulado e presença dos Latossolos Amarelos. O equilíbrio dessas áreas é determinado pelo predomínio da Floresta Estacional Semidecidual Submontana, que tem ação protetora no tocante à perda de solos na bacia, contribuindo para atenuar e até mesmo evitar processos erosivos no solo decorrente da atuação das chuvas na região, com seu regime de precipitações concentrado nos quatro primeiros meses do ano (Figura 6).

Figura 6 - Áreas de Floresta Estacional Semidecidual, contribuindo para 0 equilíbrio ambiental da bacia do Rio Preto - MA

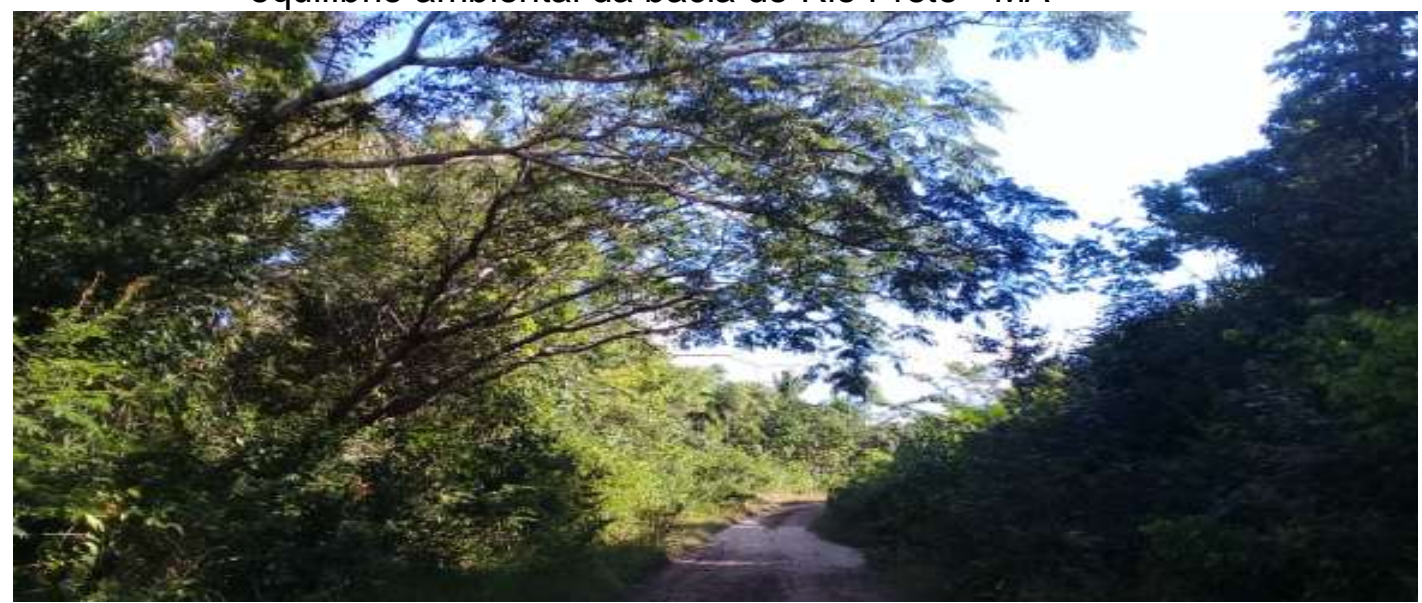

Autor: Santos (2018).

A cobertura vegetal da bacia corresponde a $76,25 \%$ da área total, constituindo uma das principais razões pela qual esse espaço é considerado estável. Essa unidade corresponde a $30,80 \%$ da bacia, corroborando com o exposto por Medeiros, Pereira e Almeida (2012, p. 482-483):

As copas das árvores impedem o gotejamento direto da precipitação no solo, evitando com isso o efeito "splash" que desagrega as partículas do 
solo; impede a compactação e consequentemente o escoamento superficial concentrado em apenas um único fluxo que é um dos principais causadores da erosão; além das raízes das espécies vegetais, que juntamente com os organismos biológicos presentes no solo, promovem a aeração, permeabilidade e porosidade.

Diante do exposto, verificou que as áreas estáveis estão correlacionadas à dinâmica da paisagem da bacia, consubstanciada pela presença da cobertura vegetal, em consonância com o tipo de solo, associada aos baixos gradientes de declividade, implicando em uma atuação menos intensa do processo morfodinâmico.

As áreas medianamente vulneráveis correspondem à classe mais abrangente da bacia, e compreende os locais com presença de Floresta Estacional Semidecidual Submontana, Savana Parque e Arborizada, e solos do tipo Argissolos Vermelhoconcrecionário, caracterizado por ser resistente à erosão e por contar com um relevo perpassando de moderadamente ondulado a ondulado, que associados aos litotipos dos Depósitos Eólicos Continentais Antigos e Depósitos Aluvionares contribuem para o equilíbrio entre a morfogênese e pedogênese na área de estudo.

Evidencia-se na bacia a presença da vegetação ciliar, juntamente com os litotipos dos Depósitos Aluvionares e a ocorrência dos solos Argissolos Vermelho-concrecionários, contribuindo para que toda a área ocupada pelo Rio Preto ficasse na categoria de medianamente vulnerável (Figura 7).

Figura 7 - Mapa de vulnerabilidade ambiental da bacia hidrográfica do Rio Preto - MA

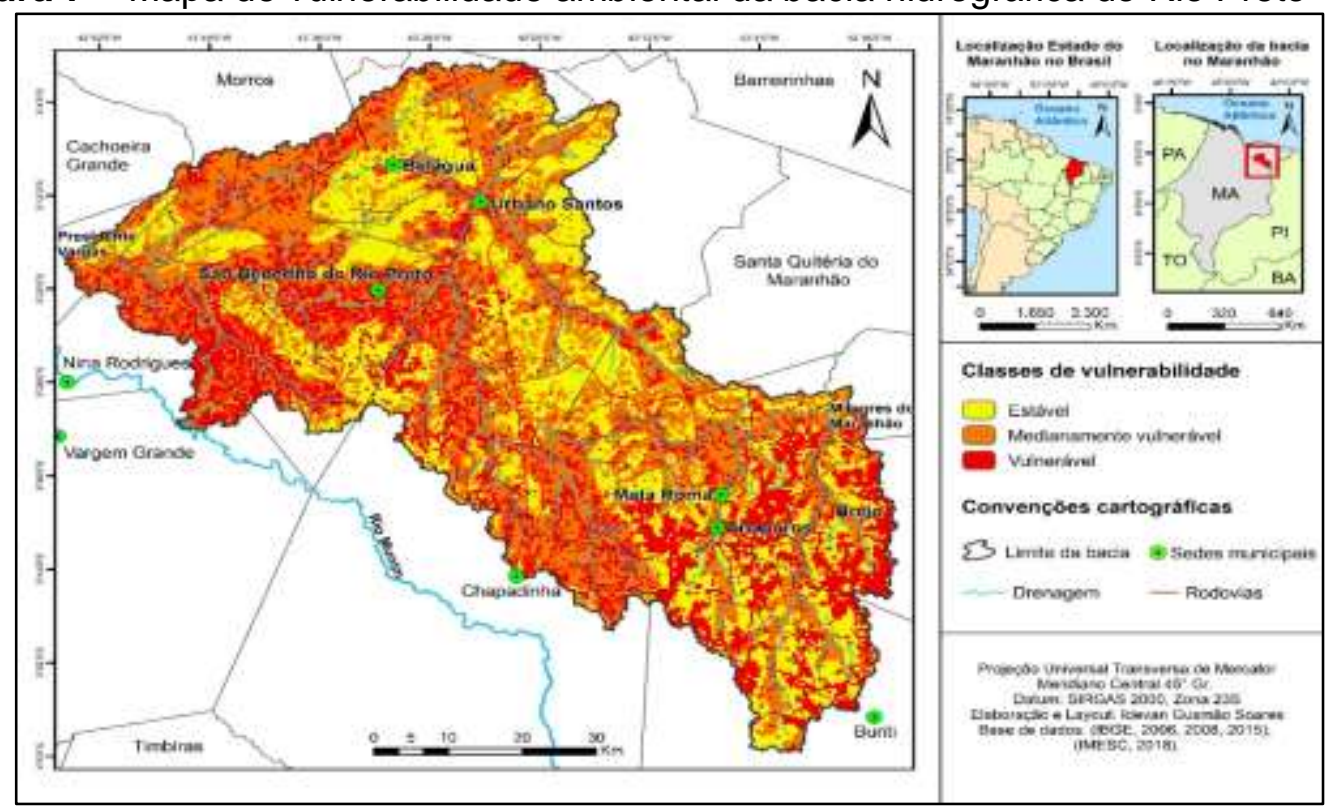

Organização: autores.

Os solos do tipo Neossolos Quartzarênicos na bacia são bastante vulneráveis, apesar da aparente profundidade, uma vez que a forte presença de areia além dos baixos teores de 
matéria orgânica e argila proporcionam a diminuição da capacidade de agregação entre as partículas deste tipo de solo. Em consequência disto, são facilmente erodidos por deflação (MEDEIROS; PEREIRA; ALMEIDA, 2012).

Por mais que os solos mencionados tenham essas características, que são a causa de sua vulnerabilidade, identificou-se, ao norte da bacia, devido às baixas declividades associadas à cobertura vegetal intercalada a corpos d'água, paleodunas e a presença dos litotipos dos Depósitos Eólicos Continentais Antigos. Nessas áreas, ocorreu uma atenuação na vulnerabilidade, gerando um equilíbrio entre pedogênese e morfogênese, embora exista esse tipo de solo. Isso implica dizer que a declividade é o elemento mais importante para definir a vulnerabilidade na bacia, pois mesmo que os solos tendam a essa característica, com uma declividade moderada o efeito de vulnerabilização é quase nulo.

As áreas vulneráveis compreendem os espaços representados por relevo suave ondulado (2-5\%), moderadamente ondulado e forte ondulado ( $>15 \%)$, ou seja, regiões com declividade variada na bacia, assim como áreas urbanas, de solo exposto, áreas de cultivo de soja, eucalipto e agricultura de subsistência. Soma-se também a presença de solos do tipo Plintossolos Pétricos e Argilúvicos e a ocorrência dos litotipos do Grupo Barreiras, Itapecuru e da Formação Codó. Todas essas variáveis correlacionadas são as principais responsáveis pela atuação de processos morfodinâmicos mais intensos na bacia.

A existência de algumas áreas com declividades mais acentuadas, como as áreas marginais às redes de drenagem da bacia, juntamente com a ocorrência das litologias do Grupo Itapecuru, contribuiu para a atuação de processos morfodinâmicos mais intensos, tornando as áreas vulneráveis ao desenvolvimento de processos erosivos. É importante salientar que, "[...] quanto maior for à declividade e mais alta a vertente, mais fácil e veloz a descida dos materiais que se encontram nela ou no seu topo, tornando este ambiente mais instável" (MEDEIROS; PEREIRA; ALMEIDA, 2012, p. 481).

Ainda em relação à declividade, Dias (2012, p. 74-75) salienta que "[...] a própria força da gravidade, sem a presença de água superficial, devido à inclinação do relevo, sempre adiciona uma componente descendente das partículas rochosas se movendo nas encostas". Essas declividades mais acentuadas na bacia também favorecem movimentos de massa, 0 que, nesse contexto, é um risco potencial, e pode se tornar real caso sejam construídas moradias adjacentes a essas áreas declivosas.

Quanto à classe vulnerável, relaciona-se à presença do Grupo Itapecuru e da Formação Codó, associado às declividades mais expressivas na bacia e/ou áreas com cultura de soja, eucalipto e agricultura de subsistência. Essa situação pode ser evidenciada nas regiões mais externas ao canal (Figura 7).

Os procedimentos metodológicos aplicados neste trabalho permitiram verificar que a vulnerabilidade ambiental está relacionada tanto a fatores naturais (morfogênese) quanto 
antrópicos (antropogênico), entretanto, na bacia do Rio Preto, a predominância é dos processos naturais. Destaca-se, também, que o problema das atividades agrícolas na vulnerabilidade ambiental está relacionado ao modelo adotado para o manejo dos solos, deixando estes mais sensíveis à erosão (Figura 8). Essas áreas na bacia compreendem principalmente aos municípios de Mata Roma, Anapurus, Buriti, Brejo, Chapadinha, Urbano Santos e Milagres do Maranhão.

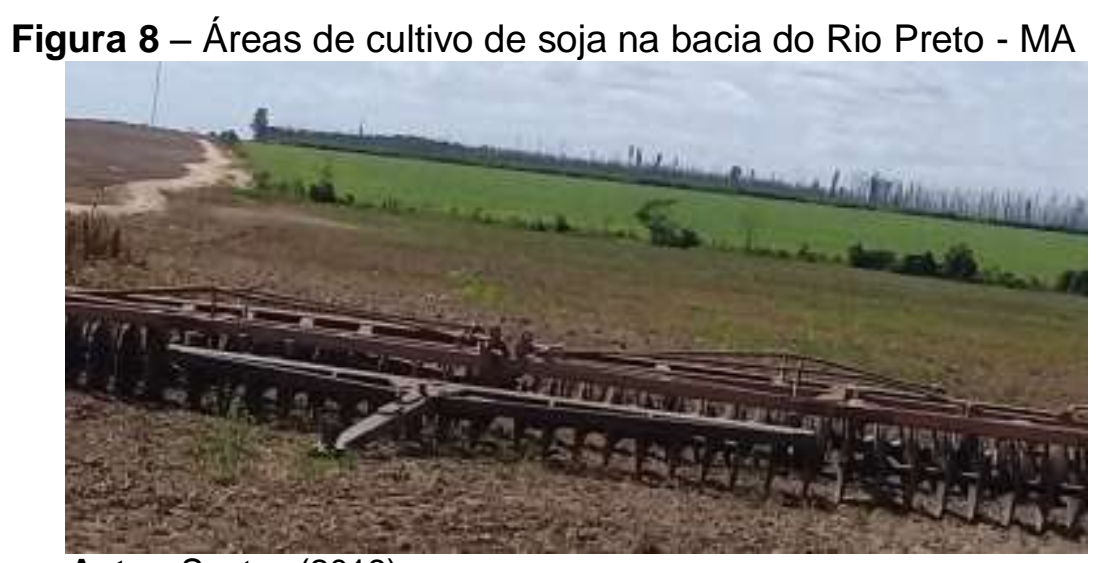

Autor: Santos (2018).

Nas áreas urbanas, principalmente nas sedes municipais, citando como exemplo Chapadinha, a condição de vulnerabilidade à erosão nos vales é mais acentuada, em função da sede encontrar-se em uma formação de chapada e alguns bairros se encontrarem em áreas escarpadas e outros em vales encaixados. Outrora, esses vales eram constituídos por riachos com água o ano todo (perenes), e atualmente estão sendo ocupados por habitação, deixando essas áreas vulneráveis à erosão.

\section{CONCLUSÃO}

O procedimento metodológico aplicado permitiu estabelecer o uso e cobertura da terra e identificar as áreas de vulnerabilidade ambiental da bacia do Rio Preto. As classes identificadas são: vulnerável, com 33,59\%, medianamente vulnerável, correspondente a $35,61 \%$ e estáveis, com $30,80 \%$. Essas áreas vulneráveis são potencialmente propensas a erosões; por este motivo, analisar a vulnerabilidade ambiental da bacia é importante, pois os sistemas não atuam de forma isolada, mas fazem parte de um conjunto maior.

O uso adequado dos recursos naturais requer o conhecimento de seu potencial e de suas limitações, a fim de aliar produção agrícola com menor impacto, ou seja, compatibilizar o uso com a conservação ambiental. Neste sentido, técnicas de cultivo e conservação dos 
solos são recomendáveis, principalmente para as áreas vulneráveis à erosão, devido ao impacto e desequilíbrio ambiental identificado nelas.

Dentre as técnicas de cultivo e conservação dos solos que podem ser utilizadas na bacia está a adubação verde, principalmente, no monocultivo de soja, e após a sua colheita pode-se plantar milheto, sorgo e feijão; sistemas de plantio direto também são aconselháveis, pois minimizam os impactos da erosão evitando a exposição do solo e a rotação de cultura, pois no sistema de monocultura somente uma espécie é cultivada até o total esgotamento do solo. Essa técnica tem como benefício o controle de pragas (através da variabilidade das espécies), a reposição de nutrientes no solo e evita a erosão.

Além das recomendações supramencionadas é importante incentivar para as áreas estáveis o cultivo agrícola que não ocupe extensas áreas, como é o caso das culturas do arroz, feijão e mandioca, que estão relacionadas a cultivos de subsistência na bacia, evitando assim a intensificação do desmatamento. Já as formações florestais que estão podem ser mantidas e ampliadas para outras áreas. No que se refere às áreas medianamente vulneráveis, seu uso deve ser limitado às atividades que não desprotejam o solo e muito menos o impermeabilize, respeitando o gradiente de declividade.

Para o uso das áreas mais instáveis deve ser levada em consideração a manutenção das áreas de preservação e, nas áreas de cultura agrícolas, com destaque para as lavouras de eucalipto e soja, aplicado o plantio direto. Além disso, deve-se manter uma orientação técnica aos camponeses para que suas atividades de subsistência estejam em consonância com o desenvolvimento sustentável.

\section{REFERÊNCIAS}

ALBINET, M.; MARGAT, J. Cartographie de la vulnérabilité à la pollution des nappes d'eau souterraine. Bulletin BRGM, Orléans, FR, v. 3, n. 4, p. 13-22. 1970.

ALLER, L.; BENNETT, T.; LEHR, J.; PETTY, R. Drastic: a standardized system for evaluating ground water pollution potential using hydrogeologic settings. Washington, DC: U.S. Environmental Protection Agency, 1987. (Report EPA/600/2-87-035).

BARROS, F. S. M.; STRAUCH, J. Mapeamento de uso e cobertura da terra da bacia hidrográfica do Rio Piraipitinga, Serrinha do Alambari, município de Resende. Revista da Pós-Graduação em Geografia da PUC-Rio, Rio de Janeiro, v. 9, n. 16, p. 6-19, jan./jul. 2016.

BATISTELLA, M.; BOLFE, E. L.; VICENTE, L. E.; VICTORIA, D. C.; ARAUJO, L. S. de. Relatório do diagnóstico do macrozoneamento ecológico-econômico do Estado do Maranhão. Campinas, SP: Embrapa Monitoramento por Satélite; São Luís, MA: Embrapa Cocais, 2013. (Relatório técnico. Embrapa monitoramento por satélite, prod. 3, v. 1).

CIVITA, M.; DE MAIO, M. SINTACS: un sistema parametrico per la valutazione e la cartografia della vulnerabilità degli acquiferi all'inquinamento. Metodologia e automazione. Bologna: Pitagora, 1997. 
COMPANHIA DE PESQUISA DE RECURSOS MINERAIS-CPRM. Downloads. Mapas geológicos estaduais. Maranhão. Brasília, DF: CPRM, 2012. Disponível em: http:// geosgb. cprm.gov.br/downloads/\#. Acesso em: 25 jun. 2019.

CREPANI, E.; MEDEIROS, J. S. de; HERNANDEZ FILHO, P.; FLORENZANO, T. G.; DUARTE, V.; BARBOSA, C. C. F. Sensoriamento remoto e geoprocessamento aplicados ao zoneamento ecológico-econômico e ao ordenamento territorial. São José dos Campos: INPE, 2001.

DIAS, V. S. B. Análise hierárquica processual (AHP) na modelagem da vulnerabilidade ambiental do microcorredor ecológico Serra das Onças (BA). 2012. Dissertação (Mestrado em Modelagem em Ciências da Terra e do Ambiente) - Universidade Estadual de Feira de Santana, Feira de Santana, 2012.

DOERFLIGER, N.; ZWAHLEN, F. EPIK: a new method for outlining of protection areas in karstic environment. In: GUNAY, G.; JOHNSON, A. I. (ed.). On karst water and environmental impacts. Rotterdam: A. A. Balkema, 1997. p. 117-223.

FERREIRA, C. C. Proposta de zoneamento ambiental das paisagens para o alto curso da bacia hidrográfica do rio Sucuriú, Mato Grosso do Sul-Brasil. 2016. Tese (Doutorado em Geografia) - Universidade Estadual Paulista, São Paulo, 2016.

FOSTER, S. S. D.; HIRATA, R. Avaliação do risco de poluição das águas subterrâneas: uma metodologia baseada em dados existentes. Lima: Organização Mundial de Saúde, Organização Pan-americana de Saúde, Centro Pan-americano de Engenharia Sanitária e Ciências Ambientais, 1988.

FRANCISCO, R. F. Contribuição metodológica à estimativa da vulnerabilidade natural e perigo de contaminação de aquíferos livres granulares. 2018. Tese (Doutorado em Geociências e Meio Ambiente) - Universidade Estadual Paulista, São Paulo, 2018.

GRIGIO, A. M. Aplicação de Sensoriamento Remoto e Sistema de Informação Geográfica na determinação da vulnerabilidade natural e ambiental do município de Guamaré (RN): simulação de risco às atividades da indústria petrolífera. 2003. Dissertação (Mestrado em Geodinâmica e Geofísica) - Universidade Federal do Rio Grande do Norte, Natal, 2003.

INSTITUTO MARANHENSE DE ESTUDOS SOCIOECONÔMICOS E CARTOGRÁFICOS IMESC. Zoneamento Econômico Ecológico do Estado do Maranhão. Base de dados: escala 1:1.000.000. Disponível em: http:// www. zee. ma. gov.br/Portal/basededados. Acesso em: 28 mar. 2019.

INSTITUTO NACIONAL DE METEOROLOGIA - INMET. Normais climatológicas do Brasil (1981-2010). Brasília - DF. Disponível em:

http://www.inmet.gov.br/portal/index.php?r=clima/normaisClimatologicas. Acesso em: 30 jul. 2019.

INSTITUTO NACIONAL DE PESQUISAS ESPACIAIS - INPE. TOPODATA: Banco de Dados Geomorfométricos do Brasil. 2011. Disponível em: http://www.webmapit.com.br/inpe/topodata/. Acesso em: 30 mar. 2019.

KLAIS, T. B. A.; DALMAS, F. B.; MORAIS, R. P; ATIQUE, G.; LASTORIA, G.; PARANHOS FILHO, A. C. Vulnerabilidade natural e ambiental do município de Ponta Porã, Mato Grosso do Sul, Brasil. Revista Ambiente \& Água, Taubaté, SP, v. 7, n. 2, p. 277-290, 2012.

LE GRAND, H. System for evaluating contamination potential of some waste sites.

American Water Work Association Journal, Denver, CO, v. 56, n. 8, p. 959-974, 1964.

LEPSCH, I.F. (coord.). Manual para levantamento utilitário do meio físico e classificação de terras no sistema de capacidade de uso. Campinas: SBCS, 1991.

LOPES, E. C. S; TEIXEIRA, S. G. Contexto Geológico. In: BANDEIRA, I. C. N. (org.). Geodiversidade do estado do Maranhão. Teresina: CPRM, 2013, p.17-30. 
MARANHÃO. Lei ordinária no 9.956 de 21 de novembro de 2013. Dispõe sobre a instituição do Comitê da Bacia Hidrográfica do Rio Munim, de acordo com art. 43, V, da Constituição do Estado do Maranhão, c/c art. 29, III, da Política Estadual de Recursos Hídricos - Lei oㅡ 8.149, de 15 de junho de 2004. São Luís: Secretaria de Transparência e Controle do Estado do Maranhão, 2013.

MARANHÃO. Secretaria de Estado de Meio Ambiente e Recursos Naturais. Proposta para implantação do comitê da bacia hidrográfica do rio Munim: estratégias de divulgação, mobilização e sensibilização social. São Luís, MA: SEMA, 2006. (Relatório técnico - CPMRT 015/06, v. 1).

MEDEIROS, M. D.; PEREIRA, V. H. C.; ALMEIDA, L. Q. Áreas de vulnerabilidade ambiental na zona Oeste de Natal/ RN/ Brasil. Revista GEONORTE, Manaus, AM, , v. 1, n. 4, p.474486, 2012. Edição especial.

PRESOTI, A. E. P. Avaliação de impactos ambientais da sojicultura em um ecossistema aquático da microrregião de Chapadinha, MA. 2008. Dissertação (Mestrado em Sustentabilidade de Ecossistemas) - Universidade Federal do Maranhão, São Luís, 2008.

SPÖRL, C. Metodologia para elaboração de modelos de fragilidade ambiental utilizando redes neurais artificiais. 2007. Tese (Doutorado em Geografia) - Universidade de São Paulo, São Paulo, SP, 2007.

TAGLIANI, C. R. A. técnica para avaliação da vulnerabilidade ambiental de ambientes costeiros utilizando um sistema geográfico de informação. In: SIMPÓSIO BRASILEIRO DE SENSORIAMENTO REMOTO, 11., 2003, Belo Horizonte, MG. Anais eletrônicos [...]. São Paulo: INPE, 2003. p. 1657-1664.

TRICART, J. Ecodinâmica. Rio de Janeiro: IBGE-SUPREN, 1977.

UNITED STATES. Geological Survey - USG. Earth Resources Observation and Science. EarthExplorer. Imagem de satélite. Canal 6, 5, 4. Órbita 220 Ponto 062 e 063. Washington, DC: USGS, 2017. Disponível em: http://earthexplorer.usgs.gov/. Acesso em: 27 jul. 2019.

VAN STEMPVOORT, D.; EWERT, L. WASSENAAR, L. AVI: a method for groundwater protection mapping in the prairie provinces of Canada. Prairie Provinces Water Board, 1992. Ottawa, CAN: Prairie Provinces Water Board, 1992.

WINCANDER, R.; MONROE, J. S. Essentials of geology. São Paulo: Cengage Learning, 2009.

Recebido: maio de 2019. Aceito: setembro de 2019. 